\title{
Aerosol Optical Properties Retrieved from a Prede Sky Radiometer over an Urban Site of Beijing, China
}

\author{
Huizheng CHE \\ Key Laboratory for Atmospheric Chemistry (LAC), Institute of Atmospheric Composition, \\ Chinese Academy of Meteorological Sciences (CAMS), China \\ Guangyu SHI
}

State Key Laboratory of Numerical Modeling for Atmospheric Sciences and Geophysical Fluid Dynamics (LASG), Institute of Atmospheric Physics, Chinese Academy of Sciences, China

Hujia ZHAO

Key Laboratory for Atmospheric Chemistry (LAC), Institute of Atmospheric Composition, Chinese Academy of Meteorological Sciences (CAMS), China

University of Chinese Academy of Sciences, China

Institute of Atmospheric Environment, China Meteorological Administration, China

Teruyuki NAKAJIMA

Atmosphere and Ocean Research Institute (AORI), The University of Tokyo, Kashiwa, Japan

Pradeep KHATRI, Tamio TAKAMURA

Center for Environmental Remote Sensing, Chiba University, 1-33 Yayoi-cho, Chiba, Japan

Hong WANG, Yaqiang WANG, Junying SUN, and Xiaoye ZHANG

Key Laboratory for Atmospheric Chemistry (LAC), Institute of Atmospheric Composition, Chinese Academy of Meteorological Sciences (CAMS), China

(Manuscript received 18 November 2013, in final form 21 May 2014)

\begin{abstract}
SKYNET is an international research network of ground-based Prede sky radiometers for the observation and monitoring of aerosol-cloud-radiation interactions in the atmosphere. The algorithm developed by SKYNET is SKYRAD.pack, which can be used to process the measurement data of Prede instruments. In this study, the latest SKYRAD.pack software (Version 5.0) has been used to retrieve the aerosol optical properties measured by a SKYNET Prede sky radiometer over an urban site of Beijing, China. Continuous data have been processed over a two-year period, and inversion products, including aerosol optical depth (AOD), Ångström exponent ( $\alpha$ ), volumes of different aerosol particle size distributions, and single-scattering albedos (SSA), have been analyzed.
\end{abstract}

Corresponding author: Huizheng Che and Guangyu Shi,

46 Zhong-Guan-Cun South Avenue, Beijing 100081,

China

E-mail: chehz@cams.cma.gov.cn, shigy@mail.iap.ac.cn

(C)2014, Meteorological Society of Japan 
AOD values were found to vary from 0.11 (5th percentile) to 1.14 (95th percentile) with a median of 0.34 at $500 \mathrm{~nm}$, and the maximum and minimum seasonal $\alpha$ values in Beijing were $1.05 \pm 0.36$ in summer and $0.82 \pm$ 0.39 in spring. SSA values are higher in summer and spring with a similar value of $0.96 \pm 0.03$, but lower in winter with a value of $0.93 \pm 0.04$ at $500 \mathrm{~nm}$. Aerosol particles in Beijing clearly demonstrated bimodal size distributions throughout the year: there were coarser particles in spring and finer particles in summer. The $\alpha$ values increased with AOD, indicating that fine particles play an important role in the optical properties of aerosols in Beijing. Dust type aerosol occurrence accounted for $4.1 \%, 5.1 \%, 0.5 \%$, and $1.2 \%$ of all measurements data in spring, summer, autumn, and winter, respectively, according to the dust criteria threshold $(\alpha<0.47$ and $\left.\mathrm{SSA}_{400 \mathrm{~nm}}-\mathrm{SSA}_{1020 \mathrm{~nm}}<0.018\right)$

Keywords sky radiometer; SKYRAD.pack software; aerosol optical properties; Beijing

\section{Introduction}

Aerosol particles can change the Earth's atmospheric radiation balance and affect the climate directly by absorbing and scattering solar radiation and radiation from the Earth's atmosphere (Ackerman and Toon 1981). In order to estimate the radiative effect of atmospheric aerosols within the climate system, it is of the utmost importance to accurately determine their optical and radiative properties in the atmospheric column (Holben et al. 2001). When estimating aerosol parameters, the sun-sky radiometric technique is the most accurate and widely used (Holben et al. 1998).

SKYNET (Takamura and Nakajima 2004; Nakajima et al. 2007) is a research network located principally in Asia and Europe. Currently, it is composed of nearly 70 sites, which use a globally standardized sky radiometer (Prede Co. Ltd., Japan) to make measurements and collect data. The radiative and optical properties of aerosols can be retrieved from the combination of sun-direct and sky-diffuse radiation measured by the sky radiometer through the application of inversion algorithms (Nakajima et al. 1983, 1996). Retrieved properties include single-scattering albedos (SSA), phase functions, real and imaginary parts of the refractive index, and the volumes of different aerosol particle size distributions. The effective radius and asymmetry parameters can be also determined from the volumes of different aerosol size distributions and phase functions. Aerosol optical properties obtained from SKYNET have been used to investigate temporal and spatial characteristics of aerosols for climate and environmental studies and to validate satellite remote sensing results (Higurashi and Nakajima 2002; Kim et al. 2005; Sohn et al. 2007; Pandithurai et al. 2009; Campanelli et al. 2010; Khatri et al.
2010; Takenaka et al. 2011).

Nakajima et al. (1996) implemented an original algorithm called SKYRAD.pack. This program was developed to be applied to Prede radiometers and constitutes the starting point for the SKYNET international network. Several different versions of the inversion algorithms have been proposed over the years. Currently, the SKYNET uses the SKYRAD. pack algorithm version 4.2 (Takamura and Nakajima 2004). Some researchers have used the SKYRAD. pack version 4.2 algorithm to retrieve aerosol optical properties (Che et al. 2008; Estellés et al. 2012). In version 4.2, the kernel functions are computed with the nonsphericity effects (Kobayashi et al. 2010). The latest version, the SKYRAD.pack version 5.0, uses $a$ priori estimation (Hashimoto et al. 2012).

The high aerosol burden regions, such as areas in China and India, are still not well characterized in terms of microphysical and optical properties. Beijing is a typical example of high aerosol burden regions in China because of the increasing number of motor vehicles and energy consumption. Therefore, aerosol optical property observation in this area is of common interest within the scientific community (Che et al. 2014). The aim of this study is to analyze approximately two years' worth of continuous observations made by the Prede sky radiometer in an urban site of Beijing using the latest version of the SKYRAD.pack, version 5.0. The results of this study may be taken more widely as indicative of aerosol optical properties due to the heavy anthropogenic aerosol loading in urban areas of China and other regions of East Asia.

\section{Instrumentation and retrieval method}

\subsection{Instrumentation and data}

There are two types of Prede sky radiometers, POM-01 and POM-02. The POM-01 model uses a 
silicon photodiode sensor to measure direct solar irradiance and sky radiance within a $1.0^{\circ}$ full fieldof-view for seven wavelengths of $315,400,500,675$, 870,940 , and $1020 \mathrm{~nm}$ at every 10 or 15 minutes (Uchiyama et al. 2005). Sky radiance is measured at 24 predefined scattering angles and at regular time intervals. The POM-02 model is equipped with an InGaAs detector, thus extending the wavelength to 11 wavelengths, including $315,340,380,400,500,675$, $870,940,1020,1627$, and $2200 \mathrm{~nm}$, for cloud applications. The precision of the in situ method has been estimated to be within $1 \%-2.5 \%$ depending on the wavelength (Campanelli et al. 2004).

A Prede POM-02 sky radiometer was installed in May 2008 at the Chinese Academy of Meteorological Sciences (CAMS, 116.317 E, 39.933 N, 105 $\mathrm{m})$ in the northern urban area of Beijing to measure aerosol optical properties and has been continuously running since then. In this study, data from 5 channels at $400,500,675,870$, and $1020 \mathrm{~nm}$ from June 2008 to May 2010 at Beijing were used to retrieve aerosol optical properties, including the aerosol optical depth (AOD), Angström exponent $(\alpha)$, the volumes of different aerosol particle size distributions $(\mathrm{d} V / \mathrm{d} l n r)$, and single-scattering albedos. In this study, the four seasons considered are spring (March to May inclusive), summer (June to August inclusive), autumn (September to November inclusive), and winter (December to February inclusive), as part of the investigations into the seasonal variations in aerosol optical properties. Continuous measurement data for April 2010 is unavailable because of a gap in the data due to the atmospheric conditions prevailing at the time and subsequent problems with the instrument.

\subsection{Retrieval methods}

In this study, aerosol optical properties were retrieved using SKYRAD.pack version 5.0. SKYRAD.pack is an open source software package released on the OpenCLASTR web page (http://157.82.240.167/ clastr/), which consists of two different modules called "dtform" and "sproc." The "dtform" module formats the Prede sky radiometer data so it can be processed by the "sproc" module. AODs, SSA, complex refractive indices, and aerosol particle size distributions were derived using a radiative transfer code as well as a linear and nonlinear inversion scheme (Nakajima et al. 1996).

In SKYRAD.pack version 5.0, the MLM method defined by Rodgers (2000) was used, based on the Bayesian theory:

$$
p(x \mid f)=\frac{p(f \mid x) p(x)}{p(f)}
$$

where $p$ is the probability density function and is defined as the Gaussian distribution, and $x$ and $f$ denote state and measurement vectors, respectively. In the MLM method, $x$ is chosen so that the posterior probability $p(x \mid f)$ is maximized under the conditions wherein a priori information has already been supplied. Organizing this nonlinear equation such that $p(x \mid f)=\max$, the following equation was obtained in tangential space for solution according to the Newtonian method:

$$
\begin{aligned}
x_{k+1}= & x_{k}+\left(U_{K}^{T} S_{e}^{-1} U_{k}+S_{a}^{-1}\right)^{-1} \\
& {\left[U_{K}^{T} S_{e}^{-1}\left(f-f_{k}\right)-S_{a}^{-1}\left(x_{k}-x_{a}\right)\right] }
\end{aligned}
$$

where $x_{k}$ is the solution at the $k$-th iteration step, $f_{k}=$ $f\left(x_{k}\right)$ is an observation modeled using $x_{k}, x_{a}$ is the $a$ priori value of $x, \mathrm{~S}_{e}$ is the measurement error covariance matrix, $S_{a}$ is the covariance matrix defined by $a$ priori and state values, $\mathrm{S}_{a}=\left[\left(x-x_{a}\right)\left(x-x_{a}\right)^{\mathrm{T}}\right]$, and $\mathrm{U}$ is the Jacobi matrix, $\partial f / \partial x$.

Thus, the retrieval algorithm used in version 5.0 allows for the rigorous retrieval of both the aerosol size distribution and the spectral complex refractive index.

Version 5.0 also uses an a priori volume size distribution function of a bimodal log-normal function,

$$
v(r)=\sum_{n=1}^{2} C_{n} \exp \left[-\frac{1}{2}\left(\frac{\ln r-\ln r_{m n}}{\ln S_{n}}\right)^{2}\right]
$$

where $r_{\mathrm{m} 1}=0.1 \mu \mathrm{m}, r_{\mathrm{m} 2}=2.0 \mu \mathrm{m}, S_{1}=0.4, S_{2}=0.8$, $C_{1}=1.0 \times 10^{-12}$, and $C_{2}=1.0 \times 10^{-12}$, each following reported climate values (Higurashi et al. 2000). For $a$ priori estimates of the real part $(n)$ and the imaginary part $(m)$ of the refractive index, $n$ is set as 1.50 and $m$ is set as 0.005 , both of which are spectrally independent values.

\section{Results and discussion}

\subsection{Temporal variation in AOD, $\alpha$, and SSA values in Beijing}

The monthly AOD values at 400, 500, 675, 870, and $1020 \mathrm{~nm}$ over the two years of measurements from June 2008 to May 2010 in Beijing are shown in Fig. 1. The AOD value was found to vary from 0.13 (5th percentile) to 1.44 (95th percentile) with a median of 0.43 at $400 \mathrm{~nm}, 0.11$ (5th percentile) to 1.14 (95th percentile) with a median of 0.34 at 500 $\mathrm{nm}, 0.08$ (5th percentile) to 0.84 (95th percentile) 


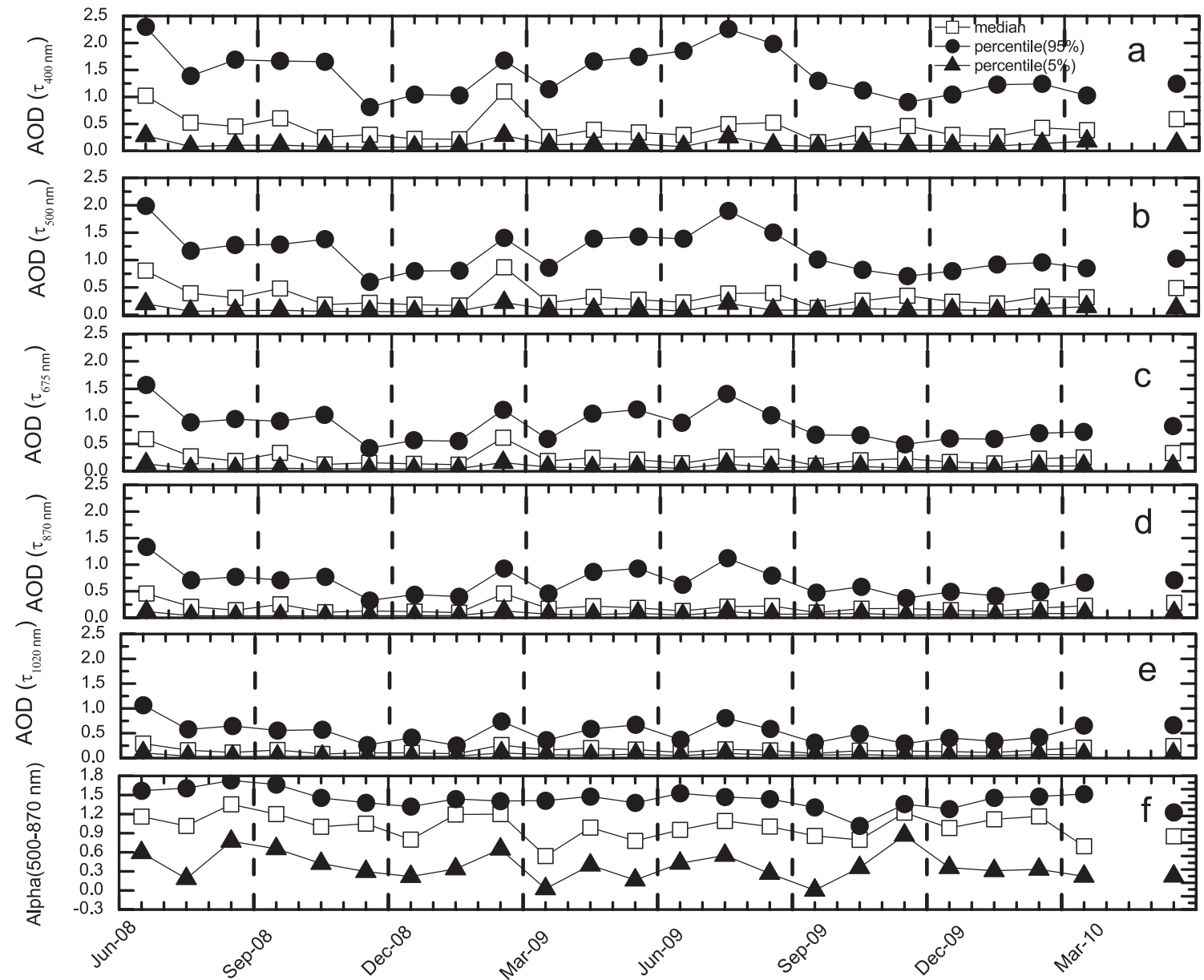

Fig. 1. Monthly AOD values at $400 \mathrm{~nm}$ (a), $500 \mathrm{~nm}$ (b), $675 \mathrm{~nm}$ (c), $870 \mathrm{~nm}$ (d), and $1020 \mathrm{~nm}$ (e), and $\alpha$ values (500-870 nm) (f) for Beijing for the period from June 2008 to May 2010.

with a median of 0.24 at $675 \mathrm{~nm}, 0.07$ (5th percentile) to 0.67 (95th percentile) with a median of 0.20 at 870 $\mathrm{nm}$, and 0.06 (5th percentile) to 0.52 (95th percentile) with a median of 0.16 at $1020 \mathrm{~nm}$. Temporal variations in Beijing indicate that the AOD increases from mid-winter to early summer and then decreases from mid-summer to early winter. The maximum (minimum) value of the AOD was recorded during May and June (December and January).

In this study, the AODs obtained at 500 and $870 \mathrm{~nm}$ have been used to calculate $\alpha$ as a qualitative indicator of aerosol size distributions (Toledano et al. 2007; Kaskaoutis et al. 2007; Masoumi et al. 2010). As Fig.1f shows, monthly $\alpha$ values were found to vary from 0.38 (5th percentile) to 1.43 (95th percentile) with a median of 1.00. The maximum and minimum values were $\sim 1.80$ and near zero or even negative, respectively.
SSA is defined as the ratio of the scattering coefficient to the extinction coefficient of a particle at a specific wavelength and varies between 0 and 1 . Its value is mostly dependent upon the chemical composition, shape, size distribution, and matter concentration of aerosol particles (Jacobson 2000). Aerosols that absorb more light have a lower SSA than purely light-scattering ones, after SSA values have been standardized (CCSP 2009). Monthly variations in SSA values at 400, 500, 675, 870, and $1020 \mathrm{~nm}$ are shown in Fig. 2. The SSA value displays a high degree of uncertainty when the AOD at $500 \mathrm{~nm}$ is lower than 0.40 (Dubovik and King 2000). In this study, all SSA values with an AOD $<0.40$ at $500 \mathrm{~nm}$ have been discounted. SSA values range from 0.88 (5th percentile) to 0.97 (95th percentile) with a median of 0.93 at $400 \mathrm{~nm}, 0.90$ (5th percentile) to 0.98 ( 95 th percentile) 


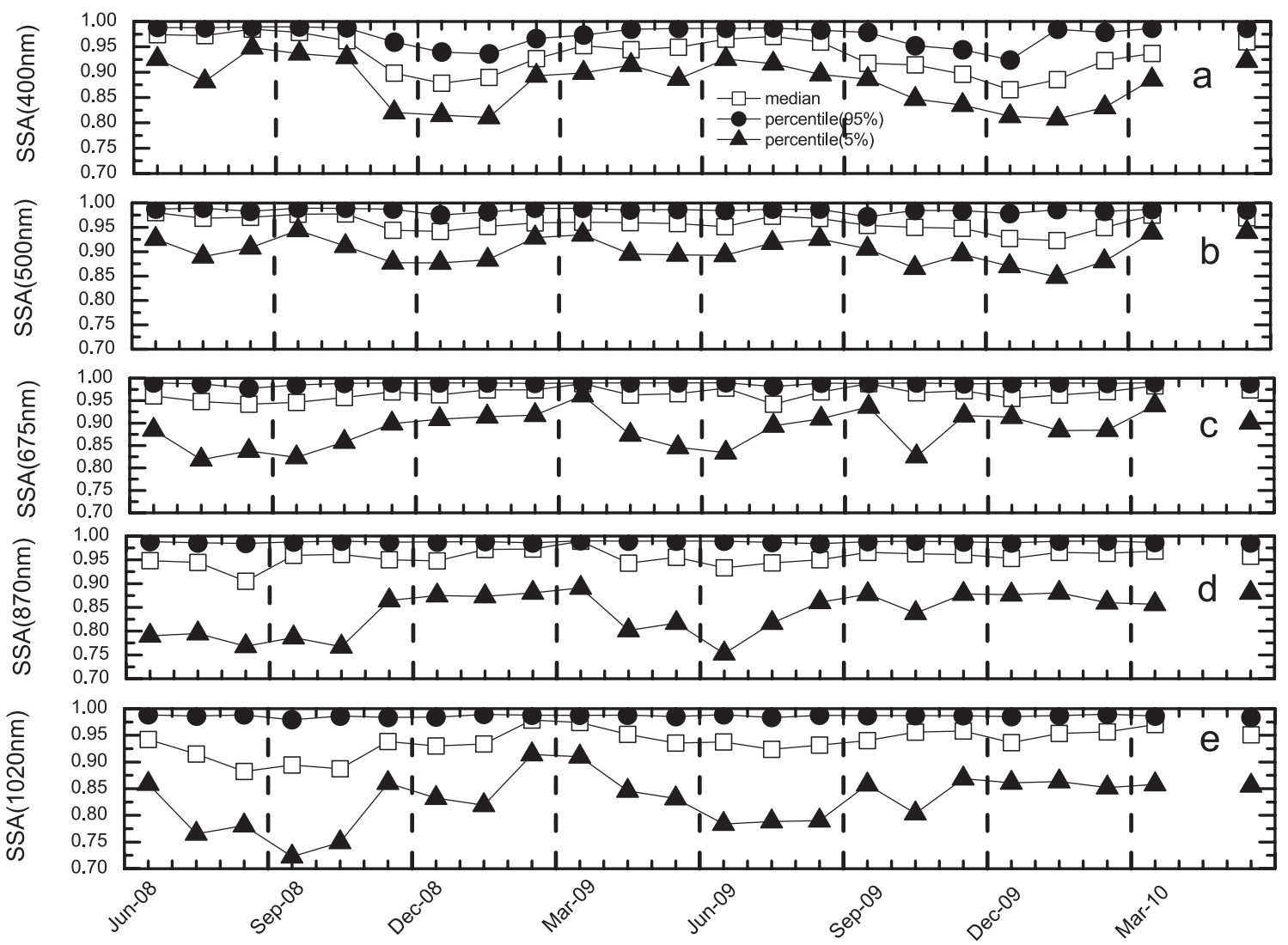

Fig. 2. Monthly SSA values at $400 \mathrm{~nm}$ (a), $500 \mathrm{~nm}$ (b), $675 \mathrm{~nm}$ (c), $870 \mathrm{~nm}$ (d), and $1020 \mathrm{~nm}$ (e) for Beijing for the period from June 2008 to May 2010.

with a median of 0.96 at $500 \mathrm{~nm}, 0.89$ (5th percentile) to 0.99 (95th percentile) with a median of 0.97 at $675 \mathrm{~nm}, 0.84$ (5th percentile) to 0.99 (95th percentile) with a median of 0.96 at $870 \mathrm{~nm}$, and 0.83 (5th percentile) to 0.99 (95th percentile) with a median of 0.94 at $1020 \mathrm{~nm}$.

\subsection{Frequency distribution of AOD, $\alpha$, and SSA values in Beijing}

The frequency distribution of AOD values at 500 $\mathrm{nm}$ and the corresponding $\alpha$ values are shown in Figs. 3 and 4 . The bin interval for the AOD and $\alpha$ values was 0.10 . Frequency histograms of AOD values at $500 \mathrm{~nm}$ showed obvious single-peak distributions. The average annual mode of readings within the range $0.00-0.50$ was $72.4 \%$, most likely reflective of local background atmospheric conditions in Beijing (Fig. 3a). The frequency distribution between 0.00 and 0.50 accounts for $69.5 \%, 59.2 \%, 76.2 \%$, and $79.0 \%$ of the total readings in spring, summer, autumn, and winter, respectively. The high aerosol burden in the atmosphere, such as the dust transported from northwest China during the spring (Wang et al. 2008b) and secondary organic aerosol particles prevalent in summer (Sun et al. 2010) may cause the large-scale depletion of the atmospheric column.

The $\alpha$ frequency histograms show differing ranges for the four seasons (Fig. 4). The frequency distribution of $\alpha$ values within the range of -0.20 to 0.40 accounts for $15.8 \%, 3.9 \%, 5.5 \%$, and $7.1 \%$ of the total readings in spring, summer, autumn, and winter, respectively. The frequency distribution of $\alpha$ values larger than 1.50 accounts for $2.6 \%, 8.6 \%, 3.4 \%$, and $1.0 \%$ of the total readings in spring, summer, autumn, and winter, respectively. These results indicate that there are larger particles present in the air in spring and winter, while there are finer particles present in summer and autumn.

The frequency distribution of SSA values between 0.90 and 0.99 accounts for $95.8 \%, 96.6 \%, 90.3 \%$, 

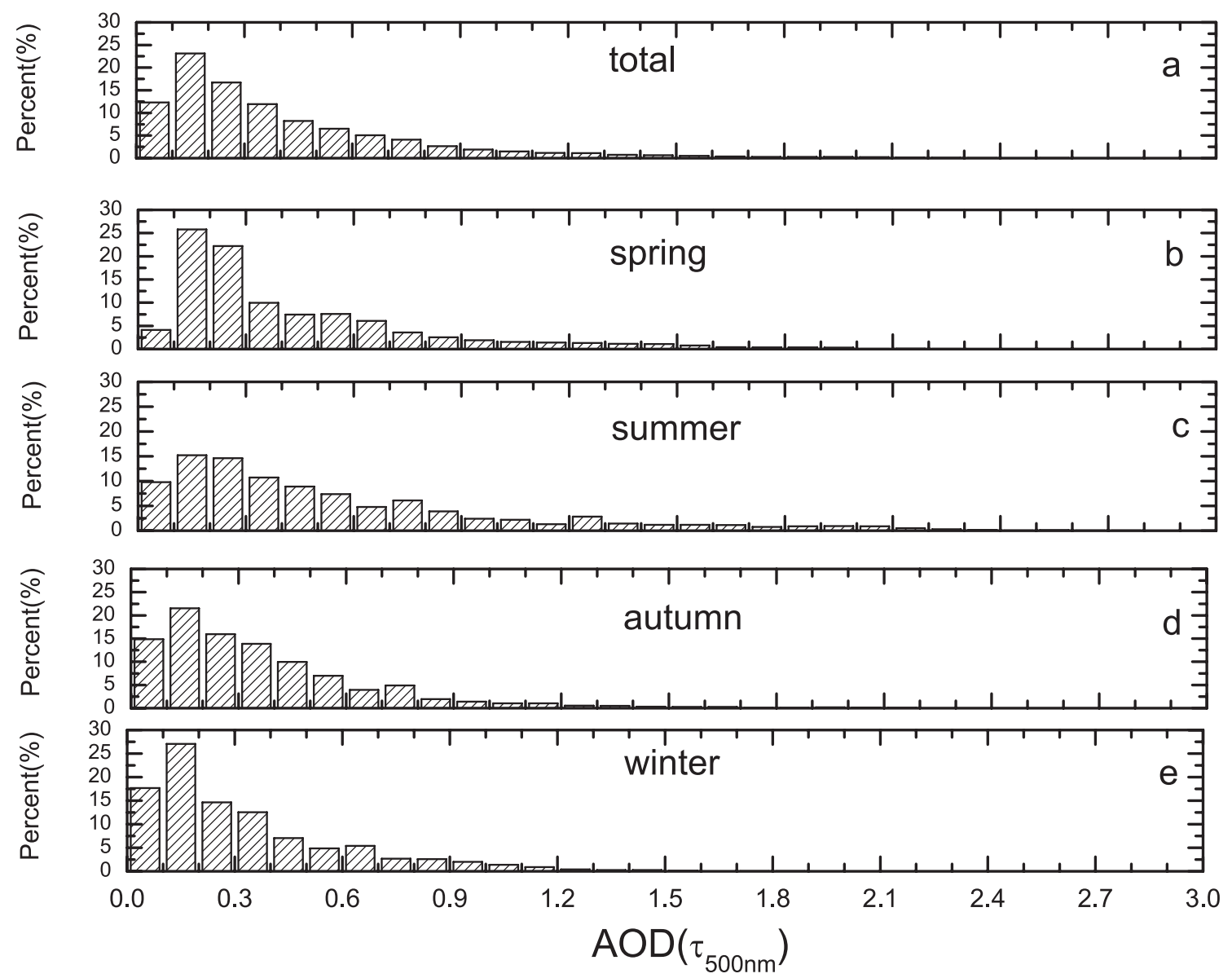

Fig. 3. Frequency distribution of average annual AOD values (a), in spring (b), summer (c), autumn (d), and winter (e) at 500nm for Beijing for the period from June 2008 to May 2010.

and $82.8 \%$ of the total readings in spring, summer, autumn, and winter, respectively (Fig. 5). The high SSA values in spring could be due to the coarse particles that are present in that season. In summer, vertical air turbulence is strong and greater numbers of particles are transported through uplift into the air. Because of the high water vapor content in the atmosphere during this period, pollutants can easily absorb moisture, grow, and finally enhance aerosol scattering (Yan et al. 2009). Approximately $17 \%$ of SSA values are less than 0.90 , which may be due to their absorption by aerosols during winter. Li et al. (2013) found that the proportion of black carbon and brown carbon particles in the air can reach between $25 \%$ and $38 \%$ during pollution events in winter.
3.3 Seasonal characteristics of AOD, $\alpha$, and SSA values in Beijing

Aerosol optical properties in Beijing exhibit significant seasonal variance. Figure 6a shows seasonal variations in AOD values at different wavelengths. The AOD decreases depending on wavelength during every season. Higher and lower AOD values at 500 $\mathrm{nm}$ occur in summer and winter with values of 0.56 \pm 0.50 and $0.33 \pm 0.28$, respectively (Table 1 ). High AOD values at $500 \mathrm{~nm}$ also occur in spring with values of $0.43 \pm 0.37$. This seasonal AOD pattern may be related to weather conditions. Dust events during spring can induce higher AOD values (Che et al. 2009). Average AOD values for the whole winter appear to be lower; this may be due to frequent cold air events. The diffusion of pollutants may be accelerated by strong winds, thus leading to lower AOD values in winter (Giavis et al. 2005). 

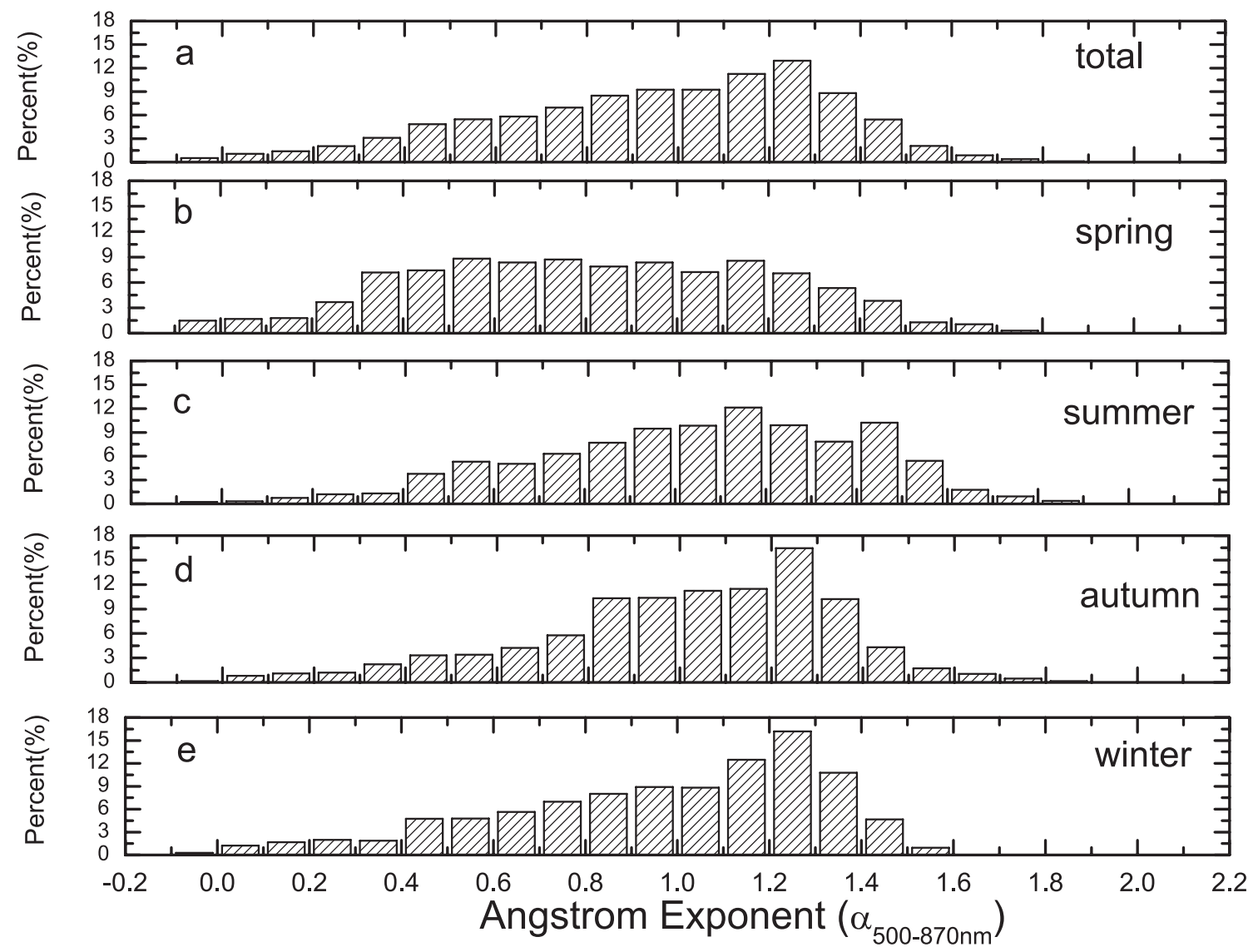

Fig. 4. Frequency distribution of average annual $\alpha$ values (a), in spring (b), summer (c), autumn (d), and winter (e) for Beijing for the period from June 2008 to May 2010.

Figure $6 \mathrm{~b}$ shows the seasonal distribution of $\alpha$ values. The boxes in Fig. $6 \mathrm{~b}$ correspond to $50 \%$ of the values' distribution (from $25 \%$ to $75 \%$ ), while the squares and lines within the boxes indicate the mean and median values, respectively. The " $x$ " and "-" symbols correspond to $1 \% / 99 \%$ and $\mathrm{min} / \mathrm{max}$ values. $\alpha$ values are higher in summer and lower in spring with values of $1.05 \pm 0.36$ and $0.82 \pm 0.39$, respectively (Table 1). $\alpha$ values are lower in spring, indicating that aerosol particle sizes are larger. This most probably is a result of the long-distance transport of dust particles from north and northwest China (Wang et al. 2011). $\alpha$ values in summer are commonly higher than in other seasons, indicating that fine particles predominate during the summer season. Pollutants are mainly industrial and are caused by man-made emissions or are the product of photochemical reactions (Sun et al. 2010).

Average SSA values are commonly higher in spring and summer with a maximum average value of $0.96 \pm$ 0.03 and lower in autumn and winter with a minimum average value of $0.93 \pm 0.04$ at $500 \mathrm{~nm}$ (Table 1).

The result above shows that the aerosol scattering ability is stronger in the spring and summer, while in autumn and winter there is a greater proportion of absorption component in the atmosphere. The value of SSA in spring is higher, which may be caused by the coarse particles from the dust events in spring. The high values of SSA in summer may have an important relation with the generation of secondary aerosol particles. Larger contents of absorption aerosols such as BC (black carbon) aerosol in winter result in lower SSA values.

Figure $6 \mathrm{c}$ also shows seasonal average SSA values for wavelengths of $400,500,675,870$, and 1020 $\mathrm{nm}$. SSA values vary between 0.89 and $0.96,0.93$ and $0.96,0.94$ and $0.96,0.93$ and 0.95 , and 0.91 and 0.93 during spring, summer, autumn, and winter, 


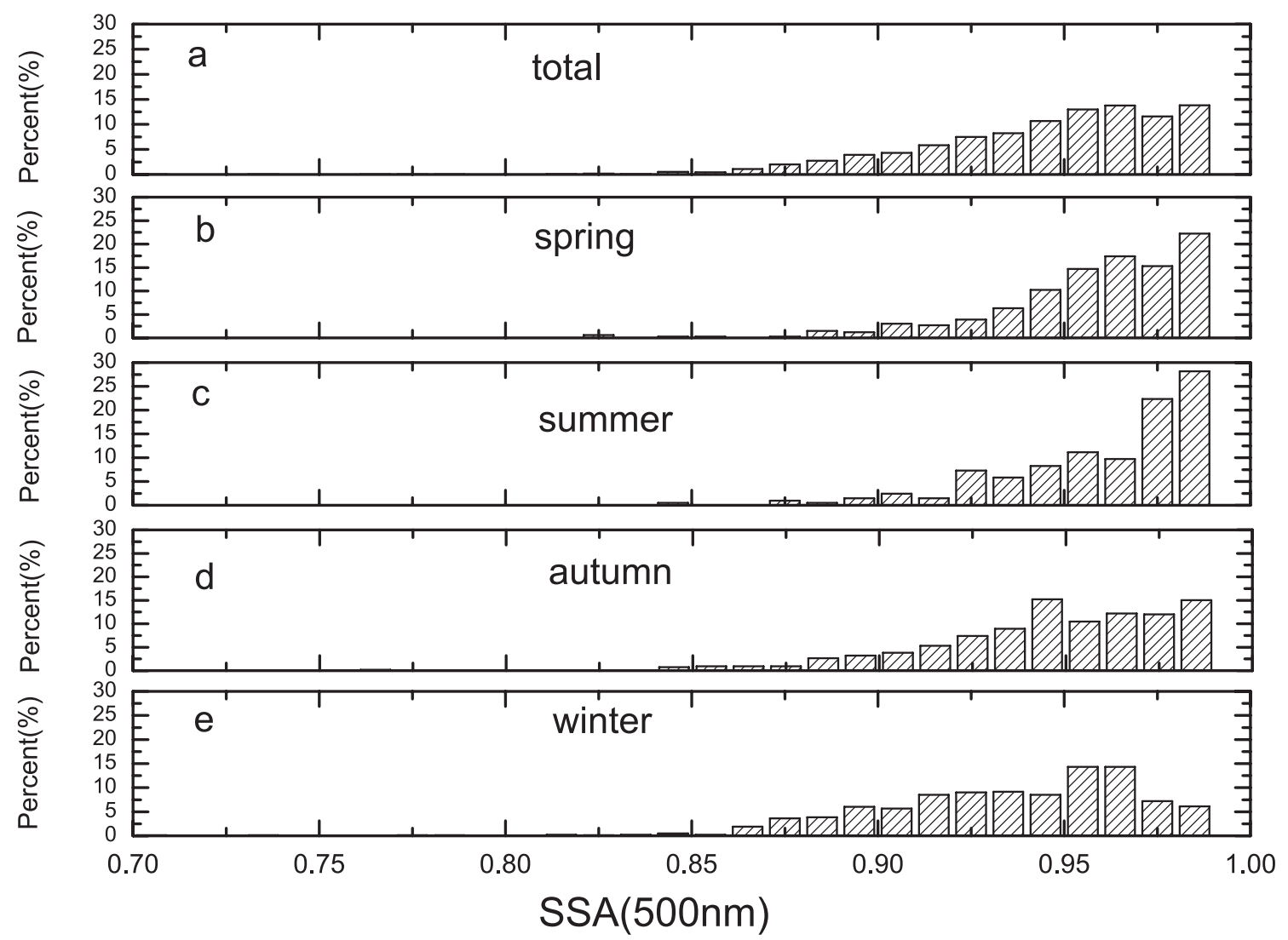

Fig. 5. Frequency distribution of average annual SSA values (a), in spring (b), summer (c), autumn (d), and winter (e) for Beijing for the period from June 2008 to May 2010.

respectively, for these 5 different wavelengths. For two infrared wavelengths (870 $\mathrm{nm}$ and $1020 \mathrm{~nm})$, SSA values showed a slightly decreasing trend with increasing wavelengths; however, for visible wavelengths (400 $\mathrm{nm}$ and $500 \mathrm{~nm}$ ), the SSA values showed an increasing trend. In summer, the SSA values showed a significant decreasing trend from 500 to $1020 \mathrm{~nm}$. During the other seasons, the SSA values showed an increasing trend with middle wavelengths (500 $\mathrm{nm}$ and $675 \mathrm{~nm})$.

\subsection{Seasonal aerosol volume size distributions in Beijing}

Aerosol size properties are one of the most important sources of information for both the observation and modeling of radiative forcing (Dusek et al. 2006). Aerosol size distributions vary greatly under different atmospheric conditions such as clear air or heavy pollution episodes. Figures. $7 \mathrm{a}-\mathrm{d}$ show the seasonally averaged volumes of different aerosol particle size distributions $(\mathrm{d} V / \mathrm{d} l n r)$ for spring, summer, autumn, and winter in Beijing. These particle size distributions show typical bimodal patterns during every season. In spring, the effective radii of fine and coarse mode particles are about 0.12 and $3.80 \mu \mathrm{m}$, respectively, whereas in summer, the effective radii are about 0.18 and $3.80 \mu \mathrm{m}$, respectively. Fine mode volumes exhibit effective radii of 0.15 $\mu \mathrm{m}$ in autumn and $0.10 \mu \mathrm{m}$ in winter, while coarse mode volumes show effective radii of $4.00 \mu \mathrm{m}$ in both autumn and winter.

Size distributions show distinct differences in their dominant modes for the different seasons. In spring, the volume of coarse aerosol particles relative to the whole is much larger than for other seasons, probably due to the presence of dust particles of a relatively large size (Wang et al. 2010). However, in summer, the volume of fine mode aerosol particles is larger in relation to the total volume of particles as compared to other seasons, indicating that mainly fine particles 

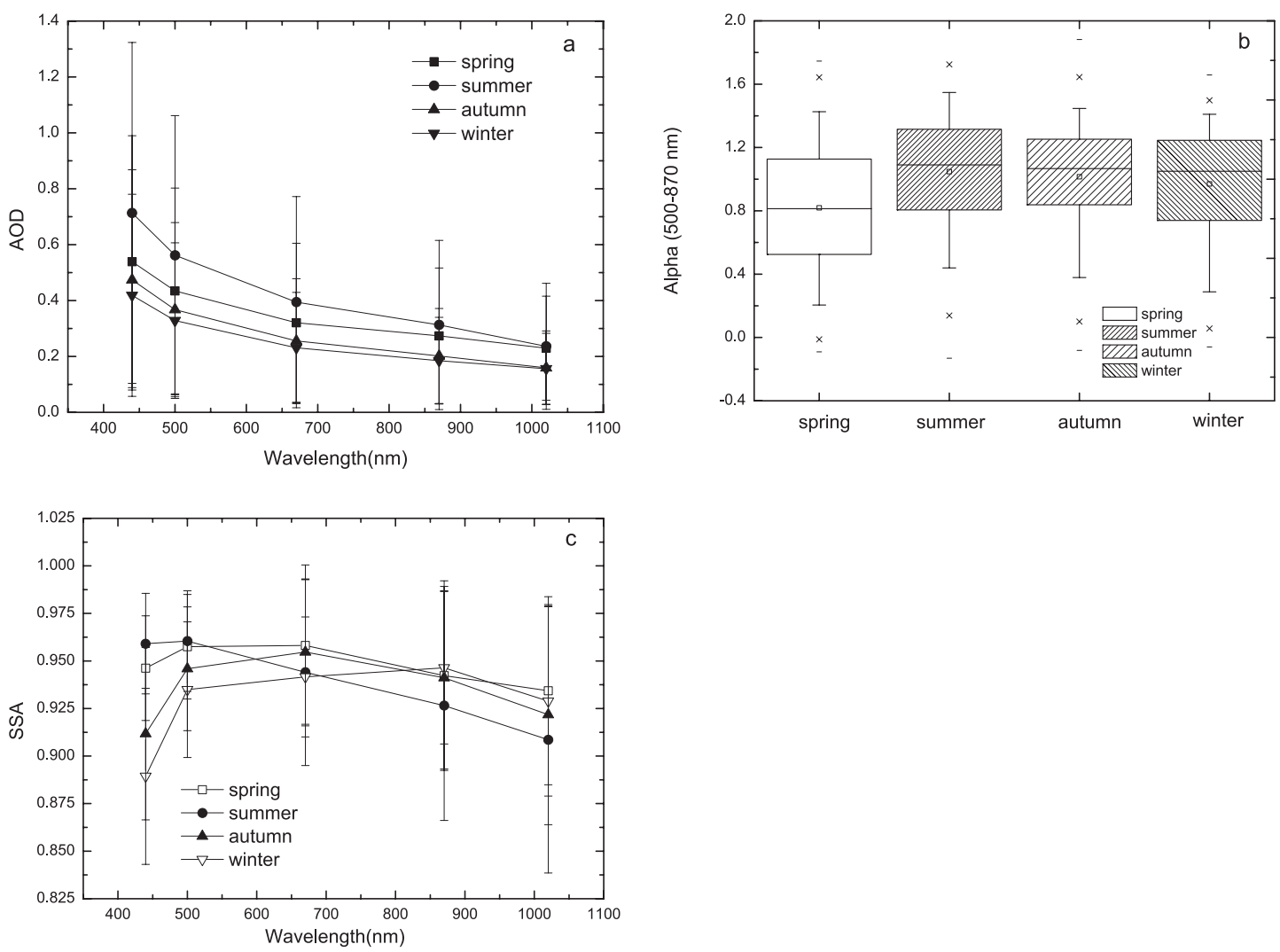

Fig. 6. Seasonal variations in AOD (a), $\alpha$ (b), and SSA (c) for Beijing for the period from June 2008 to May 2010.

Table 1. Seasonal AOD and SSA values at 400, 500, 675, 870, and $1020 \mathrm{~nm}$ and $\alpha$ values (500-870 nm) for Beijing for the period from June 2008 to May 2010.

\begin{tabular}{cccccccccccc}
\hline & $\mathrm{AOD}_{400}$ & $\mathrm{AOD}_{500}$ & $\mathrm{AOD}_{675}$ & $\mathrm{AOD}_{870}$ & $\mathrm{AOD}_{1020}$ & $\mathrm{SSA}_{400}$ & $\mathrm{SSA}_{500}$ & $\mathrm{SSA}_{675}$ & SSA $_{870}$ & SSA $_{1020}$ & Alpha $_{500-870 \mathrm{~nm}}$ \\
\hline Spring & $0.54 \pm 0.45$ & $0.43 \pm 0.37$ & $0.32 \pm 0.28$ & $0.27 \pm 0.24$ & $0.23 \pm 0.19$ & $0.95 \pm 0.03$ & $0.96 \pm 0.03$ & $0.96 \pm 0.04$ & $0.94 \pm 0.05$ & $0.93 \pm 0.05$ & $0.82 \pm 0.39$ \\
Summer & $0.71 \pm 0.61$ & $0.56 \pm 0.50$ & $0.39 \pm 0.38$ & $0.31 \pm 0.30$ & $0.24 \pm 0.23$ & $0.96 \pm 0.03$ & $0.96 \pm 0.03$ & $0.94 \pm 0.05$ & $0.93 \pm 0.06$ & $0.91 \pm 0.07$ & $1.05 \pm 0.36$ \\
Autumn & $0.47 \pm 0.39$ & $0.37 \pm 0.31$ & $0.26 \pm 0.22$ & $0.20 \pm 0.17$ & $0.16 \pm 0.13$ & $0.91 \pm 0.05$ & $0.95 \pm 0.03$ & $0.95 \pm 0.04$ & $0.94 \pm 0.05$ & $0.92 \pm 0.06$ & $1.02 \pm 0.33$ \\
Winter & $0.42 \pm 0.36$ & $0.33 \pm 0.28$ & $0.23 \pm 0.20$ & $0.18 \pm 0.16$ & $0.16 \pm 0.13$ & $0.89 \pm 0.05$ & $0.93 \pm 0.04$ & $0.94 \pm 0.03$ & $0.95 \pm 0.04$ & $0.93 \pm 0.05$ & $0.97 \pm 0.35$ \\
\hline
\end{tabular}

contribute to aerosol optical properties in summer. This increase in the volume of fine mode particles may be related to the growth of anthropogenic aerosol particles with strong hygroscopicity on summer days when water vapor content was found to be high ( $\mathrm{Li}$ et al. 2010). The size distribution for autumn and winter exhibits a mixture of both fine and coarse mode particles.

\subsection{Relations between AOD, $\alpha$, and SSA values in Beijing}

A scatter graph of instantaneous AOD and $\alpha$ values is shown in Figs. 8a-d. We can see from the scatter graph that higher $\alpha$ values accompany an increase in AOD values for all four seasons, evincing the urban aerosol characteristics typical of Beijing. Kim et al. (2004) demonstrated that the increase in AODs alongside increased $\alpha$ values is related to the year-long accumulation process of urban aerosols. High AOD values are related to the presence of fine particles, 

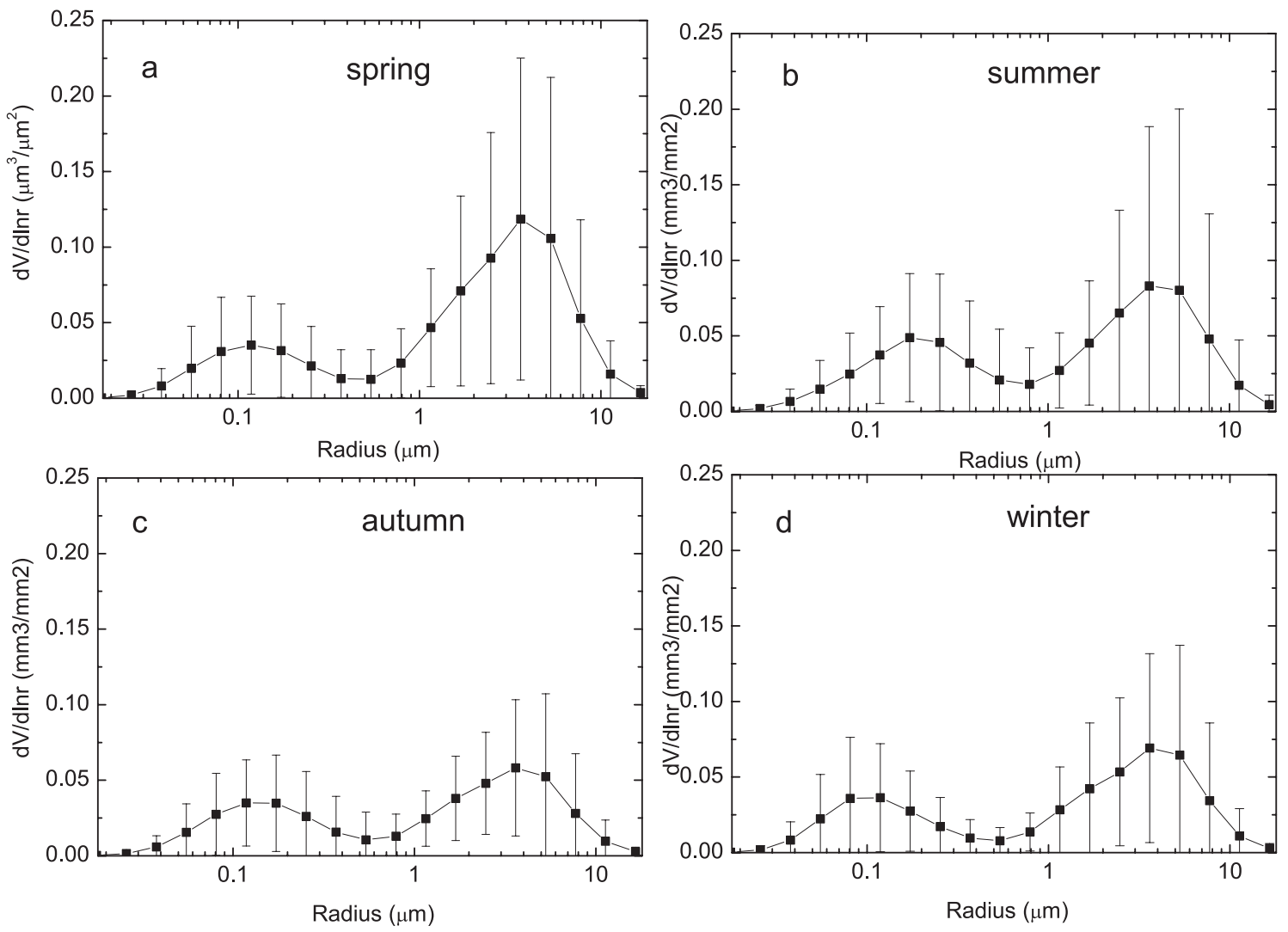

Fig. 7. Seasonally averaged volumes of different aerosol particle size distributions for Beijing for the period from June 2008 to May 2010.

which play an important role in the aerosol optical properties of Beijing.

Figures $9 \mathrm{a}$ and $9 \mathrm{~b}$ show the scatter graph of SSA and $\alpha$ values at $400 \mathrm{~nm}$ and $1020 \mathrm{~nm}$. The frequency for $\alpha>0.80$ and SSA $<0.90$ at $400 \mathrm{~nm}$ is $53.9 \%$ and the frequency for $\alpha>0.80$ and SSA $>0.90$ at 1020 $\mathrm{nm}$ is about $69.2 \%$. This means that the absorption of fine particles occurs with a greater intensity at short wavelengths and becomes more scattered over infrared wavelengths. During dust events, $\alpha$ values are lower while AOD values are higher, and the $\left(\mathrm{SSA}_{400}\right.$ $\mathrm{nm}-\mathrm{SSA}_{1020 \mathrm{~nm}}$ ) value is negative. In the past, dust criteria have been determined after conducting multiple sensitivity tests using both the mean and standard deviation. In this study, the dust criteria were set as $\alpha<0.47$ and $\mathrm{SSA}_{400 \mathrm{~nm}}-\mathrm{SSA}_{1020 \mathrm{~nm}}<0.018$. Figures $10 \mathrm{a}-\mathrm{d}$ show the scatter graphs of $\mathrm{SSA}_{400 \mathrm{~nm}}-$ $\mathrm{SSA}_{1020 \mathrm{~nm}}$ and $\alpha$ values for the four different seasons. Under these dust criteria, dust type aerosol accounts for $4.1 \%, 5.1 \%, 0.5 \%$, and $1.2 \%$ of total readings in spring, summer, autumn, and winter, respectively. Dust occurrence probability is higher in spring and summer than in autumn and winter. These dust cases could probably be caused by both the natural dust transportation (Zhang et al. 2003) and local fugitive dust emissions in Beijing (Fan et al. 2009). Fugitive or open emissions can dominate the potential environmental impacts of a chemical process. The dust occurrence is significantly increased in spring possibly because of dust events, while in summer, the reason is most likely the strong vertical turbulence which induces more particles to be transported into the air.

The dust occurrence in summer is more close to that in spring. This may be because of an obvious decreasing trend of long term variation of dust events in North China during recent decades (Wang et al. 2010). In addition, the longer and stronger solar irradiation during summer favors the photochemical formation of secondary aerosol particles, which are the major constituents of $\mathrm{PM}_{2.5}$ (Wang et al. 2008a). 

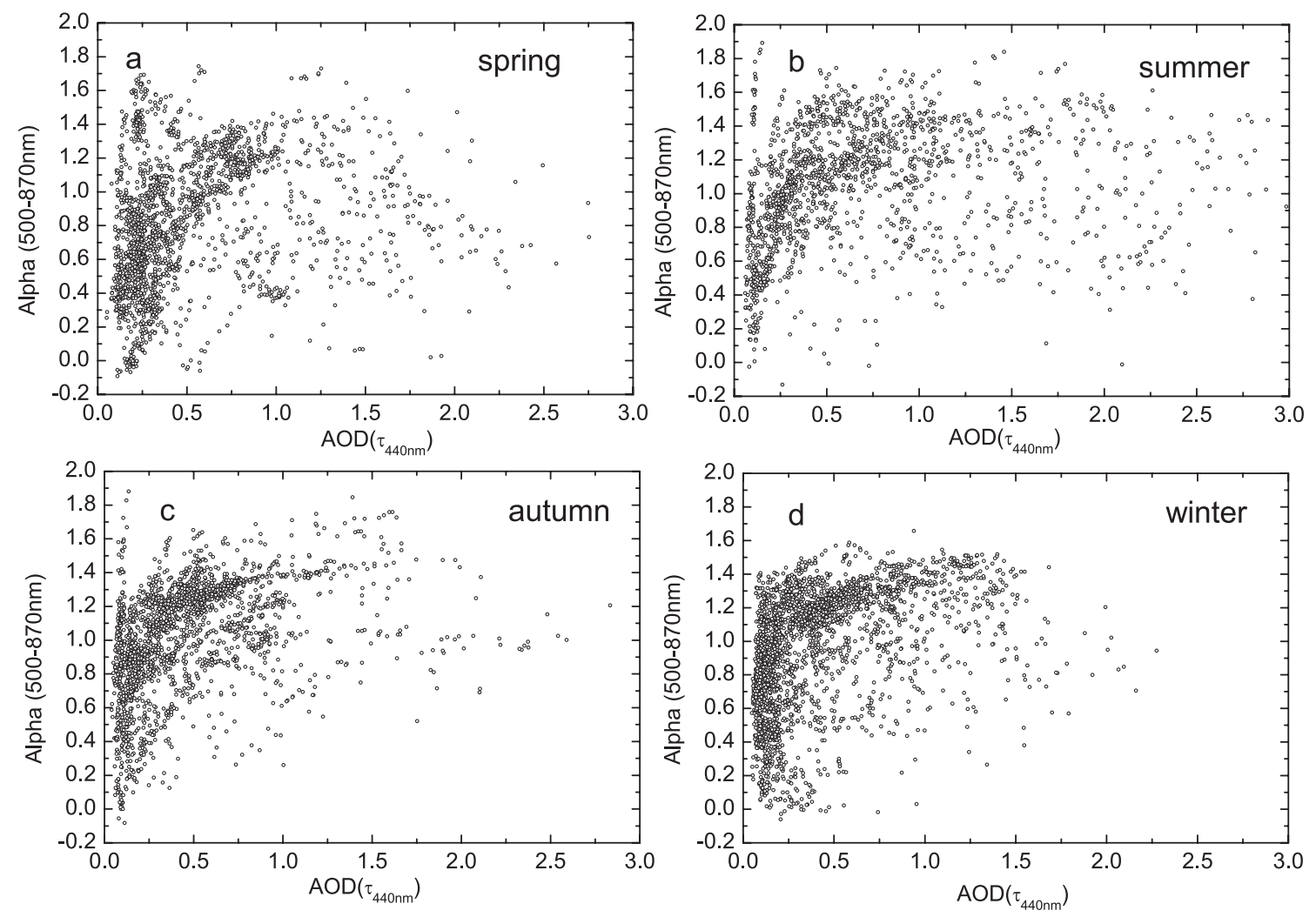

Fig. 8. Seasonal scatter graphs of AOD at $500 \mathrm{~nm}$ versus $\alpha$ values $(500-870 \mathrm{~nm})$.

Fine particles may increase the fugitive emissions in summer to a certain extent. Fan et al. (2009) pointed out that the highest fugitive dust emission of Beijing occurred during summer. Zhang et al. (2012) assessed the major chemical compositions in $<10$-micron particles using at least an entire year data from various rural and urban sites in 16 areas of the world. The concentration level of mineral aerosols in China, which is partially a result of sand and dust transported from desert areas and contributions from urban fugitive dust/fly ash sources, is found to be almost equivalent to or even higher than the sum of all kinds of aerosols in urban Europe and North America.

All the above reasons could contribute to the higher dust occurrence probability during summer in Beijing than during spring.

\section{Summary}

Aerosol optical properties over an urban site of Beijing were investigated continuously over two years using sky radiometer measurement data. The results can be summarized as follows.
The AOD values in the urban region of Beijing was found to vary from 0.11 (5th percentile) to 1.14 (95th percentile) with a median of 0.34 at $500 \mathrm{~nm}$. The maximum and minimum $\alpha$ values are $1.05 \pm 0.36$ in summer and $0.82 \pm 0.39$ in spring. SSA values are higher in summer and spring but lower in winter, suggesting more absorption by aerosol particles in winter than in other seasons.

The frequency distribution of AOD values within the range $0.00-0.5$ accounts for $69.5 \%, 59.2 \%, 76.2$ $\%$, and $79.0 \%$ of the total readings in spring, summer, autumn, and winter, respectively. The frequency of $\alpha$ values between -0.20 and 0.40 is greater than 15 $\%$ in spring but less than $8 \%$ in the other seasons. However, the frequency of $\alpha>1.50$ is greater than $8 \%$ in summer while it is less than $4 \%$ in the other seasons. These results indicate that there are coarser particles in the air in spring and finer particles in summer. The frequency distribution of SSA values within the range $0.90-0.99$ accounts for $95.8 \%, 96.6$ $\%, 90.3 \%$, and $82.8 \%$ of the total readings in spring, summer, autumn, and winter, respectively, suggesting 

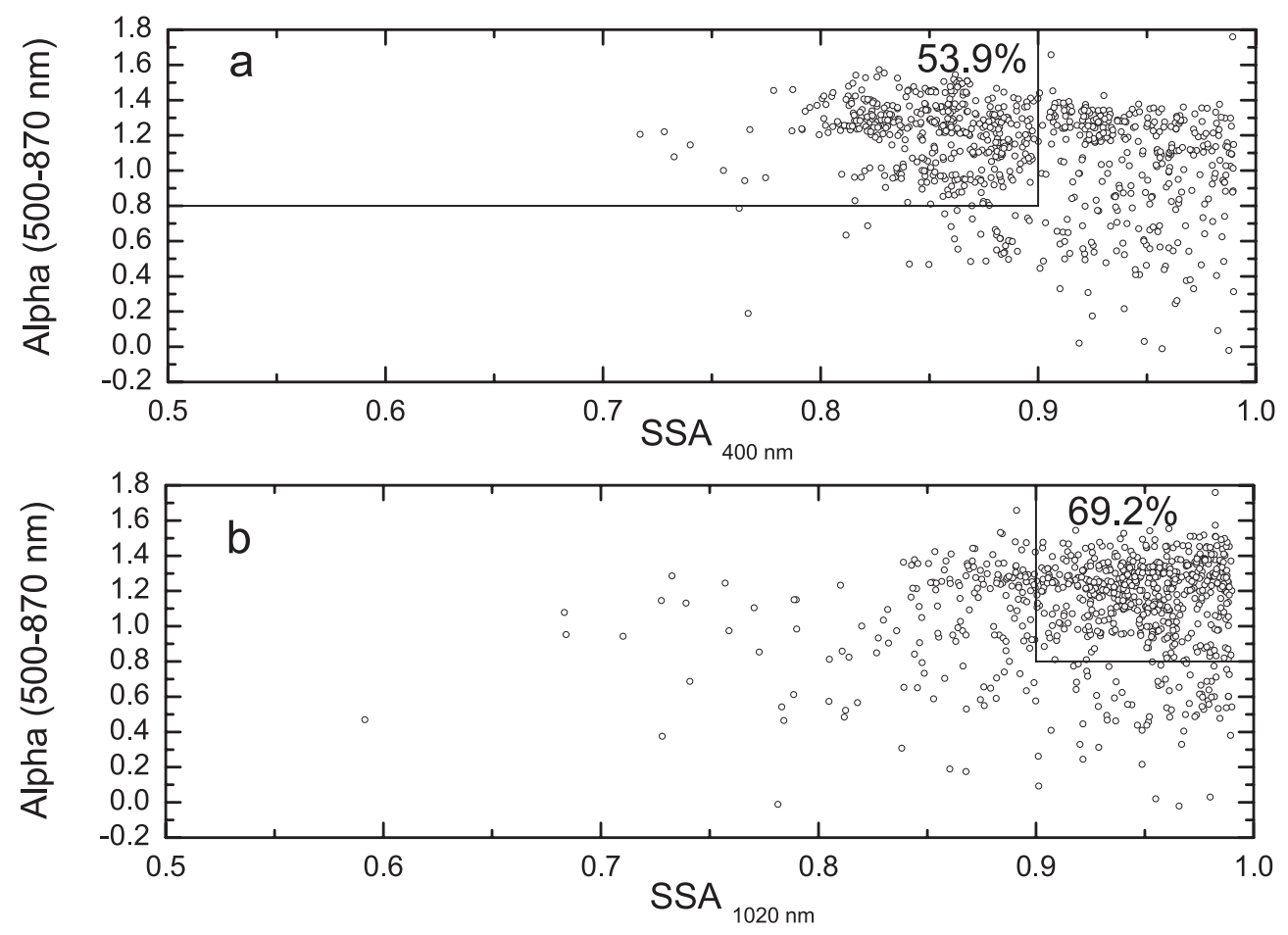

Fig. 9. Seasonal scatter graphs of SSA values at 400 (a) and 1020 (b) nm versus $\alpha$ values (500-870 nm).
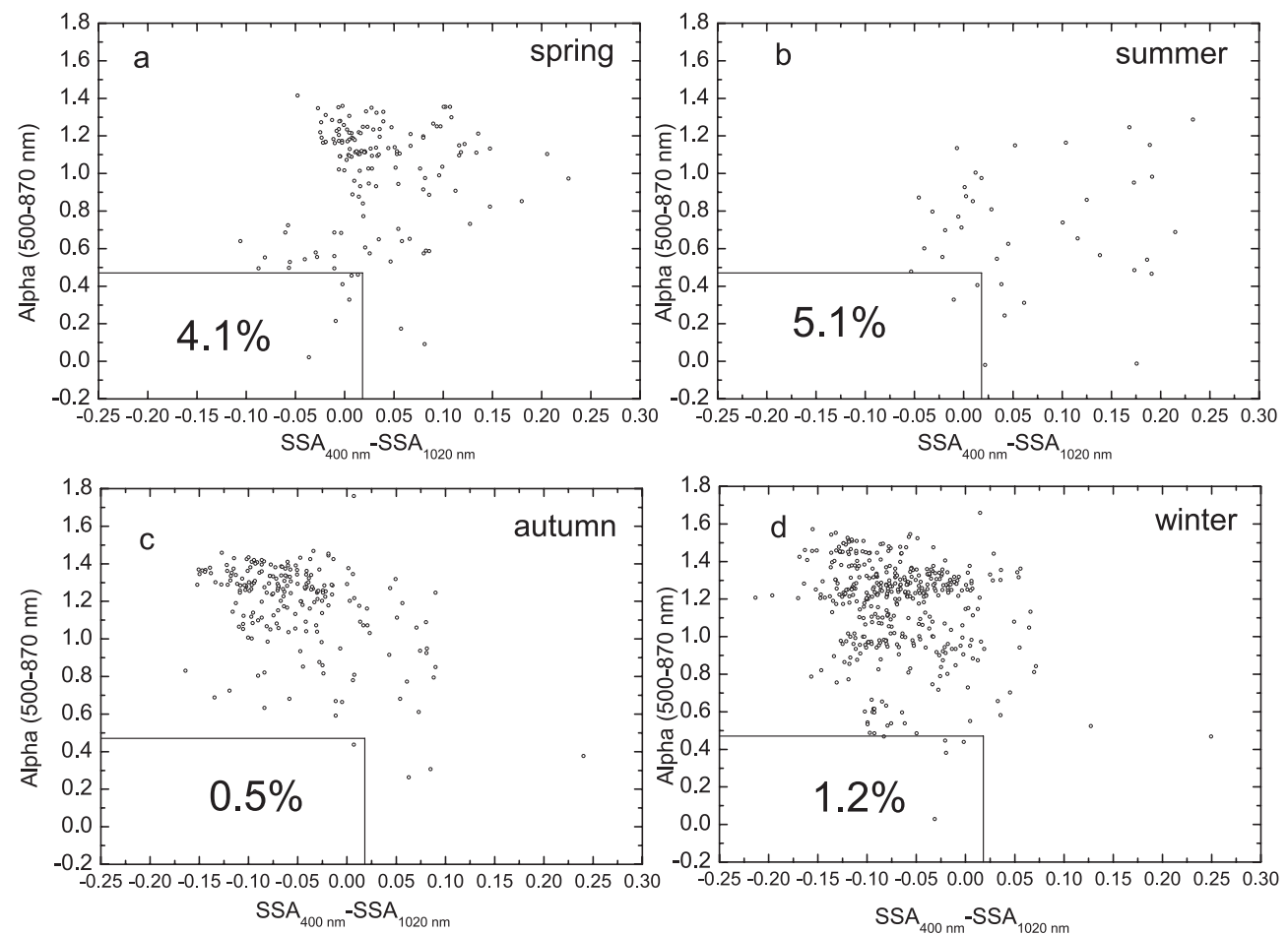

Fig. 10. Seasonal scatter graphs of SSA values between $400 \mathrm{~nm}$ and $1020 \mathrm{~nm}$ versus $\alpha$ values $(500-870 \mathrm{~nm})$. 
that there are more absorbent aerosol particles present in winter than in the other seasons.

The effective radii of fine mode particles is larger in summer than in the other seasons, while the effective radii of coarse mode particles in autumn and winter is larger than in spring and summer. With an increase in AOD values, the $\alpha$ value begins to increase, indicating that fine particles play an important role in the aerosol optical properties of Beijing. Dust type aerosol occurrence accounted for $4.1 \%, 5.1 \%, 0.5 \%$, and $1.2 \%$ of all measurements data in spring, summer, autumn, and winter, respectively.

\section{Acknowledgments}

This work was financially supported by the Project (41375153 and 41130104) supported by NSFC, grants from the National Key Project of Basic Research (2014CB441201), CAMS Basis Research Project (2013Z007), and the Meteorological Special Project of China (GYHY-200906038 \& 201206037). This work was also supported by the Jiangsu Collaborative Innovation Center for Climate Change.

\section{References}

Ackerman, P., and O. B. Toon, 1981: Absorption of visible radiation in atmosphere containing mixtures of absorbing and nonabsorbing particles. Appl. Opt., 20, 3661-3668.

Campanelli, M., A. Lupi, T. Nakajima, V. Malvestuto, C. Tomasi, and V. Estellés, 2010: Summertime columnar content of atmospheric water vapor from groundbased Sun-sky radiometer measurements through a new in situ procedure. J. Geophys. Res., 115, D19304, doi:10.1029/2009JD013211.

Campanelli, M., T. Nakajima, and B. Olivieri, 2004: Determination of the solar calibration constant for a sun-sky radiometer: Proposal of an in-situ procedure. Appl. Opt., 43, 651-659.

CCSP, 2009: Atmospheric aerosol properties and climate impacts, a report by the U.S. Climate Change Science Program and the Subcommittee on Global Change Research. Chin, M. K., A. Ralph., and E. S. Schwartz (eds.), National Aeronautics and Space Administration, Washington, D. C., USA, 128 pp.

Che, H. Z., X. Y. Zhang, A. Stephane, C. Bernadette, G. Laurent, and J. Q. Zhao, 2009: Aerosol optical properties and its radiative forcing over Yulin, China in 2001 and 2002. Adv. Atmos. Sci., 26, 564-576.

Che, H., X. Xia, J. Zhu, Z. Li, O. Dubovik, B. Holben, P. Goloub, H. Chen, V. Estellés, E. Cuevas-Agulló, L. Blarel, H. Wang, H. Zhao, X. Zhang, Y. Wang, J. Sun, R. Tao, X. Zhang, and G. Shi, 2014: Column aerosol optical properties and aerosol radiative forcing during a serious haze-fog month over North China Plain in
2013 based on ground-based sunphotometer measurements. Atmos. Chem. Phys., 14, 2125-2138.

Che, H. Z., G. Y. Shi, A. Uchiyama, A. Yamazaki, H. Chen, P. Goloub, and X. Y. Zhang, 2008: Intercomparison between aerosol optical properties by a PREDE skyradiometer and CIMEL sunphotometer over Beijing, China. Atmos. Chem. Phys., 8, 3199-3214.

Dubovik, O., and M. D. King, 2000: A flexible inversion algorithm for the retrieval of aerosol optical properties from sun and sky radiance measurements. $J$. Geophys. Res., 105, 20673- 20696.

Dusek, U., G. P. Frank, L. Hildebrandt, J. Curtius, J. Schneider, S. Walter, D. Chand, F. Drewnick, S. Hings, D. Jung, S. Borrmann, and M. O. Andreae, 2006: Size matters more than chemistry for cloud-nucleating ability of aerosol particles. Science, 312, 1375-1378.

Estellés, V., M. Campanelli, Smyth, M. P. Utrillas, F. Expósito, and J. A. Martínez-Lozano, 2012: Comparison of AERONET and SKYRAD4.2 inversion products retrieved from a Cimel CE318 sunphotometer. Atmos. Meas. Tech., 5, 569-579.

Fan, S., G. Tian, G. Li, Y. Huang, J. Qin, and S. Cheng, 2009: Road fugitive dust emission characteristics in Beijing during Olympics Game 2008 in Beijing, China. Atmos. Environ., 43, 6003-6010.

Giavis, G. M., H. D. Kambezidis, A. K. Basdekis, N. Sifakis, Z. Toth, A. D. Adamopoulos, and D. Zevgolis, 2005: Cases of aerosol optical depth estimation in the Athens area, Greece. J. Atmos. Sol. Terr. Phys., 67, 1524-1532.

Hashimoto, M., T. Nakajima, O. Dubovik, M. Campanelli, H. Che, P. Khatri, T. Takamura, and G. Pandithurai, 2012: Development of a new data-processing method for SKYNET sky radiometer observations. Atmos. Meas. Tech., 5, 2723-2737.

Higurashi, A., and T. Nakajima, 2002: Detection of aerosol types over the East China Sea near Japan from fourchannel satellite data. Geophys. Res. Lett., 29, 1836. doi:10.1029/2002GL015357.

Higurashi, A., T. Nakajima, B. Holben, A. Smirnov, R. Frouin, and B. Chatenet, 2000: A study of global aerosol optical climatology with two-channel AVHRR remote sensing. J. Climate, 13, 2011-2027.

Holben, B. N., D. Tanré, A. Smirnov, T. F. Eck, I. Slutsker, N. Abuhassan, W. W. Newcomb, J. S. Schafer, B. Chatenet, F. Lavenu, Y. J. Kaufman, J. V. Castle, A. Setzer, B. Markham, D. Clark, R. Frouin, R. Halthore, A. Karneli, N. T. O’Neill, C. Pietras, R. T. Pinker, K. Voss, and G. Zibordi, 2001: An emerging groundbased aerosol climatology: Aerosol optical depth from AERONET. J. Geophys. Res. Atmos., 106: 1206712097.

Holben, B. N., T. F. Eck, I. Slutsker, D. Tanré, J. P. Buis, A. Setzer, E. Vermote, J. A. Reagan, Y. J. Kaufman, T. Nakajima, F. Lavenu, I. Jankowiak, and A. Smirnov, 
1998: AERONET - A federated instrument network and data archive for aerosol characterization. Remote Sens. Environ., 66, 1-16.

Jacobson, M. Z., 2000: A physically-based treatment of elemental carbon optics: Implications for global direct forcing of aerosols. Geophys. Res. Lett., 27, 217-220.

Kaskaoutis, D. G., H. D. Kambezidis, N. Hatzianastassiou, P. G. Kosmopoulos, and K. V. S. Badarinath, 2007: Aerosol climatology: Dependence of the Angstrom exponent on wavelength over four AERONET sites. Atmos. Chem. Phys. Discuss., 7, 7347-7397.

Khatri, P., T. Takamura, A. Shimizu, and N. Sugimoto, 2010: Spectral dependency of aerosol light-absorption over the East China Sea region. SOLA, 6, 1-4.

Kim, D. H., B. J. Sohn, T. Nakajima, and T. Takamura, 2005: Aerosol radiative forcing over east Asia determined from ground-based solar radiation measurements. J. Geophys. Res., 110, D10S22, doi:10.1029/2004JD004678.

Kim, D. H., B. J. Sohn, T. Nakajima, T. Takamura, T. Takemura, B. C. Choi, and S. C. Yoon, 2004: Aerosol optical properties over east Asia determined from ground-based sky radiation measurements. J. Geophys. Res., 109, D02209, doi:10.1029/2003JD003387.

Kobayashi, E., A. Uchiyama, A. Yamazaki, and R. Kudo, 2010: Retrieval of aerosol optical properties based on the spheroid model. J. Meteor. Soc. Japan, 88, 847-856.

Li, W. J., L. Y. Shao, and P. R. Buseck, 2010: Haze types in Beijing and the influence of agricultural biomass burning. Atmos. Chem. Phys., 10, 8119-8130.

Li, Z. Q., X. Gu, L. Wang, D. Li, K. Li, O. Dubovik, G. Schuster, P. Goloub, Y. Zhang, L. Li, Y. Xie, Y. Ma, and H. Xu, 2013: Aerosol physical and chemical properties retrieved from ground-based remote sensing measurements during heavy haze days in Beijing winter. Atmos. Chem. Phys., 13, 1017110183.

Masoumi, A., A. Bayat, and H. R. Khalesifard, 2010: Columnar aerosol size distribution function obtained by inversion of spectral optical depth measurements for the Zanjan, Iran. Atmos. Meas. Tech. Discuss., 3, 2367-2387.

Nakajima, T., M. Tanaka, and T. Yamauchi, 1983: Retrieval of the optical properties of aerosols from aureole and extinction data. Appl. Opt., 22, 2951-2959.

Nakajima, T., G. Tonna, R. Rao, P. Boi, Y. Kaufman, and B. Holben, 1996: Use of sky brightness measurements from ground for remote sensing of particulate polydispersions. Appl. Opt., 35, 2672-2686.

Nakajima, T., S. C. Yoon, V. Ramanathan, G. Y. Shi, T. Takemura, A. Higurashi, T. Takamura, K. Aoki, B. J. Sohn, S. W. Kim, H. Tsuruta, N. Sugimoto, A. Shimizu, H. Tanimoto, Y. Sawa, N. H. Lin, C. T. Lee, D. Goto, and N. Schutgens, 2007: Overview of the atmospheric brown cloud East Asian regional experiment 2005 and a study of the aerosol direct radiative forcing in east Asia. J. Geophys. Res., 112, D24S91, doi:10.1029/2007JD009009.

Pandithurai, G., T. Takamura, J. Yamaguchi, K. Miyagi, T. Takano, Y. Ishizaka, S. Dipu, and A. Shimizu, 2009: Aerosol effect on cloud droplet size as monitored from surface-based remote sensing over East China Sea region. Geophys. Res. Lett., 36, L13805, doi:10.1029/2009GL038451.

Rodgers, C. D., 2000: Inverse Method for Atmospheric Sounding. World Scientific, Singapore, $240 \mathrm{pp}$.

Sohn, B. J., T. Nakajima, H. W. Chun, and K. Aoki, 2007: More absorbing dust aerosol inferred from sky radiometer measurements at Anmyeon, Korea. J. Meteor. Soc. Japan, 85, 815-823.

Sun, J. Y., Q. Zhang, M. R. Canagaratna, Y. M. Zhang, N. L. Ng, Y. L. Sun, J. T. Jayne, X. C. Zhang, X. Y. Zhang, and D. R. Worsnop, 2010: Highly time- and size-resolved characterization of submicron aerosol particles in Beijing using an Aerodyne aerosol mass spectrometer. Atmos. Environ., 44, 131-140.

Takamura, T., and T. Nakajima, 2004: Overview of SKYNET and its activities. Opt. Pura y Apl., 37, 3303-3303.

Takenaka, H., T. Y. Nakajima, A. Higurashi, A. Higuchi, T. Takamura, R. T. Pinker, and T. Nakajima, 2011: Estimation of solar radiation using a neural network based on radiative transfer. J. Geophys. Res., 116, D08215, doi:10.1029/2009JD013337.

Toledano, C., V. E. Cachorro, A. Berjon, A. M. de Frutos, M. Sorribas, B. A. de la Morena, and P. Goloub, 2007: Aerosol optical depth and Ångström exponent climatology at El Arenosillo AERONET site (Huelva, Spain). Quart. J. Roy. Meteor. Soc., 133, 795-807.

Uchiyama, A., A. Yamazaki, H. Togawa, and J. Asano, 2005: Characteristics of Aeolian dust observed by sky-radiometer in the Intensive Observation Period 1 (IOP1). J. Meteor. Soc. Japan, 83A, 291-305.

Wang, H. L., Y. H. Zhuang, Y. Wang, Y. L. Sun, H. Yuan, G. S. Zhuang, and Z. P. Hao, 2008a: Long term monitoring and source apportionment of $\mathrm{PM}_{2.5} / \mathrm{PM}_{10}$ in Beijing, China. J. Environ. Sci., 20, 1323-1327.

Wang, X., J. Huang, M. Ji, and K. Higuchi, 2008b: Variability of East Asia dust events and their long-term trend. Atmos. Environ., 42, 3156-3165.

Wang, X., J. Huang, R. Zhang, B. Chen, and J. Bi, 2010: Surface measurements of aerosol properties over northwest China during ARM China 2008 deployment. J. Geophys. Res., 115, D00K27, doi:10.1029/2009JD013467.

Wang, Y. F., Y. J. Ma, Z. Y. Lu, and Y. Hong, 2011: Analysis of meteorological elements and the air pollution during a sand dust weather process in 2010 in Liaoning province. J. Meteor. Environ., 27, 27-31 (in Chinese). 
Yan, P., X. L. Pan, J. Tang, X. J. Zhou, R. J. Zhang, and L. M. Zeng, 2009: Hygroscopic growth of aerosol scattering coefficient: a comparative analysis between urban and suburban sites at winter in Beijing. Particuology, 7, 52-60.

Zhang R., Y., Xu, and Z. Han, 2003: Inorganic chemical composition and source signature of PM2.5 in Beijing during ACE-Asia period. Chinese Sci. Bull., 48, 1002-1005.

Zhang, X. Y., Y. M. Zhang, and G. L. Cao, 2012: Aerosol chemical compositions of Beijing $\mathrm{PM}_{1}$ and its control coountermeasures. J. Appl. Meteor. Sci., 23, 257-264 (in Chinese). 